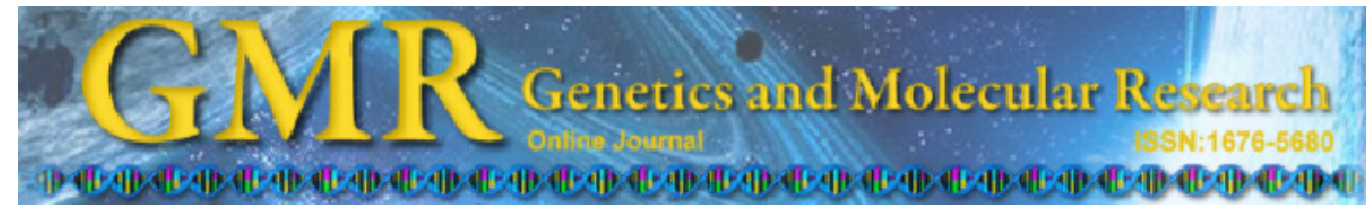

\title{
Comparative genetic diversity of wild and hatchery-produced populations of tongue sole (Cynoglossus semilaevis) using multiplex PCR assays with polymorphic microsatellite markers
}

\author{
H.S. An ${ }^{1}$, E.-M. Kim ${ }^{1}$, H.W. Kang ${ }^{3}$, H.S. Han ${ }^{3}$, J.W. Lee ${ }^{2}$, J.Y. Park', \\ J.I. Myeong ${ }^{3}$ and C.M. An ${ }^{1}$ \\ ${ }^{1}$ Biotechnology Research Division, \\ National Fisheries Research and Development Institute, Busan, Korea \\ ${ }^{2}$ Genetics and Breeding Research Center, \\ National Fisheries Research and Development Institute, Gyeongsangnamdo, Korea \\ ${ }^{3}$ Aquaculture Management Division, \\ National Fisheries Research and Development Institute, Busan, Korea \\ Corresponding author: H.S. An \\ E-mail: hsan97@korea.kr
}

Genet. Mol. Res. 12 (4): 6331-6343 (2013)

Received June 12, 2013

Accepted September 19, 2013

Published December 4, 2013

DOI http://dx.doi.org/10.4238/2013.December.4.20

\begin{abstract}
The tongue sole, Cynoglossus semilaevis (Cynoglossidae), is one of the most economically important fishery resources in Korea. This study presents a preliminary investigation of the future viability of the complete aquaculture of tongue sole in Korea. Specifically, possible differences in genetic variability between wild populations of tongue sole from Korea and hatchery-produced populations of tongue sole from China were assessed using multiplex assays with 12 polymorphic nuclear microsatellite DNA loci. High levels of polymorphism were observed between the 2 populations. A total of 135 different alleles were found,
\end{abstract}


varying from 5-15 alleles per locus, with some alleles being unique. These findings indicate a high level of genetic variability in both the wild and hatchery-produced populations. Although a considerable loss of rare alleles was observed in hatchery samples, there were no statistically significant reductions of heterozygosity or allelic diversity in the hatchery population compared to the wild population. Moreover, the inbreeding coefficient was very low $\left(F_{\text {IS }}=-0.010-0.052\right)$ for both populations. However, significant genetic heterogeneity was found between the 2 populations. These findings indicate that genetic drift has likely promoted differentiation between these 2 populations, and might have negative effects on the reproductive capacity of the stock, because genetic factors are important in the production of high quality seed for complete aquaculture. Therefore, aquaculture management should incorporate basic genetic principles into existing molecular monitoring protocols. The information compiled by this study is anticipated to provide a useful genetic basis for future complete culturing plans and management of $C$. semilaevis in fisheries.

Key words: Cynoglossus semilaevis; Tongue sole; Microsatellite; Genetic variability; Multiplex assays

\section{INTRODUCTION}

The tongue sole, Cynoglossus semilaevis, is primarily distributed throughout East Asia and is localized in the western coastal waters of Korea. Tongue sole represents a commercially valuable flatfish species in Korea; however, the production of this important fishery resource has declined in recent years. While several marine life of the intertidal zone are listed as threatened species in Korea, the tongue sole is not; however, this fish is affected by a number of human activities, such as land reclamation, pollution, and over-harvesting. To ease the pressures on wild fishery stocks and to satisfy the growing human consumption of this fish, efforts to develop tongue sole aquaculture have been initiated. Recently, for the purposes of artificial reproduction, a hatchery-produced population of C. semilaevis in China was transplanted to a local government hatchery on the western coast of Korea, in Incheon. However, the complete culturing of tongue sole, which includes reproduction control, captive spawning, hatching, and larval and juvenile rearing, is not yet possible. This delay has led to an increase in the need for genetic information about this species, as there are concerns that the process of aquaculture might be affected by genetic variability within the hatchery-produced population imported from China.

Despite the foreign origin of this hatchery-produced population of C. semilaevis, it has not undergone genetic screening; the absence of this information is potentially problematic (Allendorf and Ryman, 1987). Regardless, this transplanted tongue sole population has been successfully reared in a hatchery for six years (NFRDI, 2012). Cultured fish typically represent gene pools that are distinct from natural populations. The genetic diversity of artificial seeds is generally lower compared to that of wild populations because of unconscious selection, and the limited number of parents used to produce subsequent generations in the hatchery (Wang et al., 2011). A loss of genetic variation may lead to potential harmful effects on various commercially important traits, such as survival and growth, which would impair 
the aquaculture process (Allendorf and Ryman, 1987). Inbreeding, even in small populations, may also lead to the rapid loss of genetic variability. Parental similarity is negatively related to adult reproductive success and, wherever sample sizes are large, the relationships become significantly negative (Amos et al., 2001). Nevertheless, the maintenance of genetic diversity in hatchery-produced populations has been reported for other marine organisms (Pan and Yang, 2010; An et al., 2012b). Molecular genetic diversity in fish has been found to be associated with life history traits, which reflect habitat types (DeWoody and Avise, 2000). Therefore, it is necessary to investigate genetic variability in these wild and hatchery-produced tongue sole populations, to produce high-quality specimens for complete aquaculture.

Recently, a number of reports have been published about the isolation of various molecular markers (Wang et al., 2008; Miao et al., 2011; Sha et al., 2011), characterization of certain genes (Deng et al., 2009), and artificial gynogenesis (Chen et al., 2009) in C. semilaevis. However, reports about the current genetic diversity of the Chinese aquaculture population and the Korean wild population are not available, despite concerted efforts aimed toward developing the aquaculture of this species. Well-founded scientific data such as these are fundamental to the success of aquaculture development strategies, including the reintroduction of hatchery-bred individuals. It seems likely that transplantation would be more successful if, or when, the genetic variation of the hatchery-bred population is similar to that found in natural populations (Frankham et al., 2002).

Molecular markers have proven to be an effective indicator of genetic variation within and between the populations of many fishery animals, including fish (Yoon et al., 2011; Han et al., 2012; Hong et al., 2012; Lee and Hur, 2012). In particular, microsatellite DNA markers, or short tandem repeats (STRs), are well-known hypervariable genetic markers with great discriminating power for the evaluation of genetic diversity in various marine species (An et al., 2012a; Blanco Gonzalez et al., 2012). A relatively large number of microsatellites may be necessary to achieve sufficient statistical power, and thus, multiplex assays [i.e., the co-amplification of several microsatellite loci in single polymerase chain reactions (PCRs)] offer considerable benefits in terms of reduced labor time and laboratory costs (Caballero et al., 2012). Multiplex assays are also relevant to the development of standardized screening protocols for species of particular economic interest, and for cost-effective population genetic analyses (Olafsson et al., 2010).

The aim of this preliminary study was to assess differences in genetic diversity between wild tongue sole populations in Korea and a hatchery-produced tongue sole population from China using a multiplex PCR assay with 12 microsatellite markers. These data are a necessary foundation for understanding the genetic basis of these populations, and furthering the future goal of complete aquaculture of C. semilaevis in Korea.

\section{MATERIAL AND METHODS}

\section{Sample collection and DNA extraction}

Samples of fin-clip tissue (approximately $1 \mathrm{~cm}^{3}$ ) were obtained from wild-caught tongue sole $\left(\mathrm{N}=36\right.$; fish length $>25-30 \mathrm{~cm}$ ) from the coast of Shinan, Korea (West sea; $34^{\circ} 83^{\prime} \mathrm{N}$, $126^{\circ} 10^{\prime} \mathrm{E}$ ) in 2012 . This wild sample represents natural conditions uncontaminated by transplantation or stocking. Similarly, 39 hatchery-produced tongue sole fish were obtained from a local government hatchery at Incheon, Korea, where the artificial production of tongue sole is carried out annually. At this facility, approximately 100 breeders are kept for reproduction (5 years of 
age; fish length $>25-30 \mathrm{~cm}$ ). These breeders were originally produced at a hatchery in Weihai, China (Yellow Sea; $37^{\circ} 30^{\prime} \mathrm{N}, 122^{\circ} 09^{\prime} \mathrm{E}$ ) in 2008 and transplanted to Korea. Details about the founding and maintenance of this hatchery-reared strain are not available. All samples were stored in $2 \mathrm{~mL} 99 \%$ ethanol at $4^{\circ} \mathrm{C}$ until DNA extraction. For genotyping, total DNA from the fin-clips of each sample was extracted using an automated DNA extraction system; MagExtractor MFX-2100 (TOYOBO) with a MagExtractor-Genomic DNA Purification Kit (TOYOBO, Osaka, Japan). The extracted genomic DNA was stored at $-20^{\circ} \mathrm{C}$ until genotyping.

\section{Multiplex PCR assay}

To develop a method for the molecular screening of tongue sole from Korea based on multiplex PCR assays, 64 polymorphic microsatellite loci that had been previously characterized (Wang et al., 2008) were tested. The PCR assay development was performed with 16 wild individuals and 12 microsatellite loci (A041-24, A041-45, A041-92, A073-04, A073-29, A073-35, A073-56, A073-75, A073-79, B121-52, B121-58, and B137-30; GenBank accession numbers: EU159305-159307, EU159310, EU159316, EU159319-20, EU159323, EU159325, EU159339-40, and EU159348, respectively), which were selected for genotyping in multiplex panels based on consistent PCR amplification and clear allelic size variation (Table 1). Three PCR-based multiplex systems were utilized for genotyping. The 12 microsatellite loci were placed into 1 of 3 multiplex PCR panels depending on allelic size variation and PCR conditions: 1) A041-24, A073-75, B121-58, and A073-79 with an annealing temperature of $54^{\circ} \mathrm{C}$; 2) A041-92, A073-04, B121-52, and $\mathrm{A} 073-35$ with an annealing temperature of $52^{\circ} \mathrm{C}$; and 3 ) A041-45, A073-29, B137-30, and A073-56 with an annealing temperature of $56^{\circ} \mathrm{C}$.

\begin{tabular}{|c|c|c|c|c|}
\hline Locus & Primer sequence $\left(5^{\prime}-3^{\prime}\right)$ & $\mathrm{Ta}\left({ }^{\circ} \mathrm{C}\right)$ & Repeats & $\begin{array}{c}\text { GenBank } \\
\text { accession No. }\end{array}$ \\
\hline A041-24 & $\begin{array}{l}\text { F: GGTCCGTCCGGCACATTT fam } \\
\text { R: TAGACCCGACCCAGTGGA }\end{array}$ & $54(63)$ & $(\mathrm{TGTC})_{4}(\mathrm{TGTC})_{7}$ & EU159305 \\
\hline A041-45 & $\begin{array}{l}\text { F: AGTTAATCCTTTGTTCTCATCC fam } \\
\text { R: TCTGTAGCCGACTGTCCTG }\end{array}$ & $56(60)$ & $(\mathrm{AG})_{19}$ & EU159306 \\
\hline A041-92 & $\begin{array}{l}\text { F: TTTCTGCTCGTGCGGTAG fam } \\
\text { R: TGCAGCATGAGTGCGTTAG }\end{array}$ & $52(530$ & $(\text { AAGA })_{14}$ & EU159307 \\
\hline A073-04 & $\begin{array}{l}\text { F: CCCCAACATTAGGCAATTC vic } \\
\text { R: GGTAACATTTATCAAACCTCCA }\end{array}$ & $52(53)$ & $(\mathrm{GA})_{19}$ & EU159310 \\
\hline A073-29 & $\begin{array}{l}\text { F: CAGAGTTGCTGCTCAGTCGT vic } \\
\text { R: TGGTGTAGTCACTGCGTTGG }\end{array}$ & $56(63)$ & $(\mathrm{AC})_{14}$ & EU159316 \\
\hline A073-35 & $\begin{array}{l}\text { F: GCTGAAACAAGCAGAATGG pet } \\
\text { R: TCTATCTCCTGTTGGTCCCTA }\end{array}$ & $52(46)$ & $(\mathrm{GT})_{11}$ & EU159319 \\
\hline A073-56 & $\begin{array}{l}\text { F: GCGGCTTCCGTCTCAGGTT pet } \\
\text { R: CCTTCAAAGCGCAGCGTCA }\end{array}$ & $56(63)$ & $(\text { GGAGT })_{6}$ & EU159320 \\
\hline A073-75 & $\begin{array}{l}\text { F: TGGTTAGCGTAAGGATTTGG vic } \\
\text { R: CATGGTGCTGAAGAGTTGC }\end{array}$ & $54(60)$ & $(\mathrm{CA})_{13}$ & EU159323 \\
\hline A073-79 & $\begin{array}{l}\text { F: GCGGCTGCCTACAAACCT pet } \\
\text { R: TGGAGACGGAGCAGGGTA }\end{array}$ & $54(60)$ & $(\mathrm{TG})_{12}$ & EU159325 \\
\hline B121-52 & $\begin{array}{l}\text { F: AATGCTGAGGCTGTGATC ned } \\
\text { R: GAGGAGGAAACAGTAAGAAA }\end{array}$ & $52(63)$ & $(\mathrm{TC})_{10}$ & EU159339 \\
\hline B121-58 & $\begin{array}{l}\text { F: CCCTGCATCAGCTCACTG ned } \\
\text { R: AGAGGTTGGCTAACCTTTAG }\end{array}$ & $54(63)$ & $(\mathrm{AAAC})_{10}$ & EU159340 \\
\hline B137-30 & $\begin{array}{l}\text { F: GACCGACAGACAGACTCACAG ned } \\
\text { R: CAGACCCTCCTTCATCACC }\end{array}$ & $56(63)$ & $(\mathrm{GCA})_{5}$ & EU159348 \\
\hline
\end{tabular}

Ta is multiplex annealing temperature and Ta in baskets is primer pair original annealing temperature. 


\section{Microsatellite genotyping}

PCR amplification of the 12 microsatellite loci was performed using an ABI 9700 Thermal Cycler System (Applied Biosystems; Foster City, CA, USA) in $25 \mu \mathrm{L}$ reaction mixture containing $12.5 \mu \mathrm{L} 2 \mathrm{X}$ Multiplex PCR Pre-Mix (SolGent; Daejeon, Korea; Cat. No. SMP01-P096), $100 \mathrm{ng}$ template DNA, and $10 \mathrm{pmol}$ of each primer. The forward primer from each pair was 5'-end-labeled with 6-FAM, NED, PET, and VIC dyes (Applied Biosystems) before the samples were multiplexed for genotyping by pooling samples tagged with different dyes within a single well. PCRs were run for $15 \mathrm{~min}$ at $95^{\circ} \mathrm{C}$, followed by 30 cycles of $20 \mathrm{~s}$ at $95^{\circ} \mathrm{C}, 40 \mathrm{~s}$ at the optimal annealing temperature (Table 1), and $1 \mathrm{~min}$ at $72^{\circ} \mathrm{C}$, before a 3 -min final extension at $72^{\circ} \mathrm{C}$. For genotyping, $1 \mu \mathrm{L}$ PCR product was combined with formamide and a GeneScan-500 HD ROX size standard (Applied Biosystems), and then electrophoresed on an ABI PRISM 3130 Automated DNA Sequencer (Applied Biosystems).

\section{Population comparison}

The alleles were scored using GeneMapper (ver. 4.0; Applied Biosystems) with a size standard and an internal control for allele coding; whereby, each allele was coded by its size in nucleotide base pairs (bp). A panel that included all of the alleles detected in the 75 individuals was created for each locus. Possible null alleles and genotyping errors caused by stuttering and/or large-allele dropout were tested using MICRO-CHECKER (1000 randomizations; Van Oosterhout et al., 2004). The genetic diversity of each sample was evaluated using the number of alleles $\left(N_{\mathrm{A}}\right)$, the size $(\mathrm{S})$ and range $(\mathrm{R})$ of an allele in bp, the number of observed unique alleles $(\mathrm{U})$, the observed heterozygosity $\left(H_{\mathrm{O}}\right)$, the expected heterozygosity $\left(H_{\mathrm{E}}\right)$, and the polymorphic information content (the PIC is an indicator of the utility of the marker for linkage or population genetic studies) based on the allele frequencies pooled across all samples, as calculated by CERVUS version 3.03 (Kalinowski et al., 2007). Differences in genetic diversity parameters were tested using a nonparametric analysis (Wilcoxon signed-rank test; Wilcoxon, 1945). Deviations from the Hardy-Weinberg equilibrium (HWE) were tested using the inbreeding coefficients $\left(F_{\text {IS }}\right.$; Weir and Cockerham, 1984), as implemented in GENEPOP'007 (Rousset, 2008), for which the significance levels were adjusted for multiple tests using the sequential Bonferroni correction (Rice, 1989). The ARLEQUIN software (ver. 3.0; Excoffier et al., 2007) was used to assess linkage disequilibrium for all pairs of loci in which the empirical distribution was obtained by a permutation procedure (Slatkin and Excoffier, 1996).

The extent of population subdivision was examined by calculating the global multilocus $F_{\mathrm{ST}}$ (Weir and Cockerham, 1984) and $R_{\mathrm{ST}}$ values (1000 permutations; Rousset, 1996). The indices of the pairwise $F_{\mathrm{ST}}$ values, based on an infinite allele model (IAM), and $R_{\mathrm{ST}}$ values, based on a stepwise mutation model (SMM), were calculated using ARLEQUIN. A log-likelihood G test (Goudet et al., 1996) was performed using GENEPOP'007 to determine whether the allelic and genotypic distributions were identical between the 2 populations. The significances of $\mathrm{P}$ values across all loci for the 2 populations were determined using Fisher's probability combination test, and evaluated following the sequential Bonferroni adjustment of critical probabilities (Rice, 1989). For the analysis of 
molecular variance (AMOVA; Excoffier et al., 1992), components of variance for both within and between populations based on an IAM were estimated using ARLEQUIN (ver. 3.0; Excoffier et al., 2007). The significance of AMOVA components was tested using 1000 permutations.

\section{RESULTS}

\section{Genetic variability}

Two wild and hatchery-produced populations of $C$. semilaevis (total $\mathrm{N}=75$ ) were screened for genetic variations at 12 polymorphic microsatellite loci using the multiplex method presented here. The 12 primer sets yielded variable profiles, and reruns were performed on approximately $21 \%$ of each of the sample sets to ensure that the allele scoring was reproducible. No significant differences were observed, indicating that genotyping errors did not affect allele scoring. The amplification of the 2 tongue sole populations yielded an 87.2-97.95\% allele score in a single run (data not shown). Individual genotypes that were not scored in the first PCR assay were obtained after up to 2 additional PCR runs, simply by varying the amount of template DNA, which reduced the likelihood that the current results were affected by poor DNA quality. Two of the 75 individuals had 1 locus for which alleles could not be unambiguously characterized ( $99.8 \%$ overall success rate). MICRO-CHECKER analysis revealed that none of the loci in either population were affected by null alleles. An examination of the pair-wise linkage disequilibrium revealed that all 12 microsatellite loci were in linkage equilibrium.

All 12 microsatellite loci were polymorphic in all samples of tongue sole, and the level of polymorphism varied depending on the locus. The measures of genetic diversity for each population, as calculated from the observed allele distribution, are presented in Table 2. A total of 135 different alleles were observed at the 12 loci, with some alleles being unique to each population. Allelic diversity was 11.25 , with the number of alleles per locus ranging from 5 to 15 . Neither population had a diagnostic allele. A medium-to-high degree of polymorphism was detected per locus, with PIC values of 0.40-0.89 (Table 2). Average $H_{\mathrm{E}}$ ranged from 0.453 to 0.896 , and average $H_{\mathrm{O}}$ ranged from 0.401 to 0.960 .

The difference in genetic diversity was also reflected in the wild and hatchery-produced samples. Allele frequencies at all 12 loci selected in each sample are presented (Table 3; Figure 1), and reveal differences between the samples. Fewer alleles were found in the hatchery-produced population compared to the wild population (total number of alleles: 121 versus 101) and the average $H_{\mathrm{E}}$ value of the wild population tended to be higher compared to that of the hatchery-produced population $(0.763$ versus 0.748$)$. Average $F_{\text {IS }}$, including all markers, was 0.052 in the hatchery-produced sample and 0.010 in the wild sample (Table 2). Forty-eight alleles were found to be unique to a single population (Tables 2 and 3), and the hatchery-produced population had fewer unique alleles compared to the wild population (14 versus 34). However, despite these differences in genetic diversity, no significant differences in the average measures were observed between the wild and hatchery-produced populations (Wilcoxon signed-rank test, $\mathrm{P}>0.05$ ). 


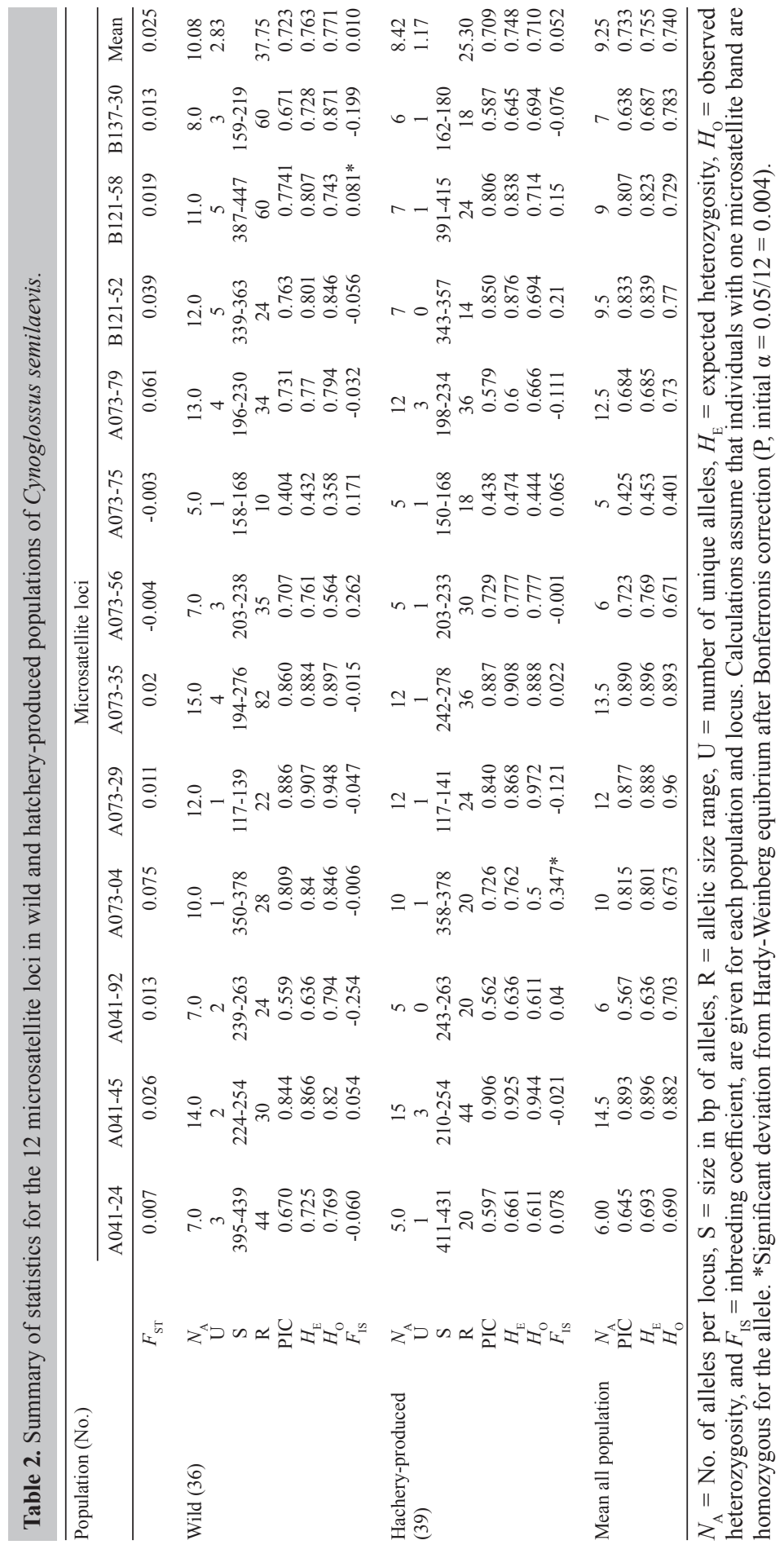




\begin{tabular}{|c|c|c|c|c|c|c|c|}
\hline Loci & Allele & Wild & Hachery & Loci & Allele & Wild & Hachery \\
\hline \multirow[t]{8}{*}{ A041-24 } & 395 & 0.014 & 0.000 & A073-56 & 203 & 0.139 & 0.192 \\
\hline & 411 & 0.000 & 0.051 & & 208 & 0.278 & 0.256 \\
\hline & 419 & 0.306 & 0.231 & & 213 & 0.319 & 0.269 \\
\hline & 423 & 0.028 & 0.077 & & 218 & 0.181 & 0.269 \\
\hline & 427 & 0.125 & 0.231 & & 223 & 0.028 & 0.000 \\
\hline & 431 & 0.486 & 0.410 & & 228 & 0.042 & 0.000 \\
\hline & 435 & 0.028 & 0.000 & & 233 & 0.000 & 0.013 \\
\hline & 439 & 0.014 & 0.000 & & 238 & 0.014 & 0.000 \\
\hline \multirow{19}{*}{ A041-45 } & 210 & 0.000 & 0.013 & A $073-75$ & 150 & 0.000 & 0.038 \\
\hline & 218 & 0.000 & 0.051 & & 158 & 0.014 & 0.000 \\
\hline & 224 & 0.028 & 0.000 & & 162 & 0.708 & 0.744 \\
\hline & 228 & 0.000 & 0.038 & & 164 & 0.111 & 0.115 \\
\hline & 230 & 0.056 & 0.013 & & 166 & 0.125 & 0.038 \\
\hline & 232 & 0.083 & 0.000 & & 168 & 0.042 & 0.064 \\
\hline & 234 & 0.083 & 0.115 & & & & \\
\hline & 236 & 0.056 & 0.064 & A073-79 & 196 & 0.014 & 0.000 \\
\hline & 238 & 0.111 & 0.308 & & 198 & 0.028 & 0.090 \\
\hline & 240 & 0.111 & 0.064 & & 202 & 0.625 & 0.385 \\
\hline & 242 & 0.069 & 0.090 & & 204 & 0.056 & 0.026 \\
\hline & 244 & 0.069 & 0.051 & & 206 & 0.069 & 0.269 \\
\hline & 246 & 0.069 & 0.103 & & 208 & 0.014 & 0.026 \\
\hline & 248 & 0.083 & 0.026 & & 210 & 0.014 & 0.013 \\
\hline & 250 & 0.139 & 0.038 & & 212 & 0.000 & 0.038 \\
\hline & 252 & 0.014 & 0.013 & & 218 & 0.014 & 0.000 \\
\hline & 254 & 0.028 & 0.013 & & 220 & 0.014 & 0.000 \\
\hline & & & & & 222 & 0.028 & 0.000 \\
\hline & & & & & 226 & 0.014 & 0.026 \\
\hline \multirow[t]{8}{*}{ A041-92 } & 239 & 0.014 & 0.000 & & 228 & 0.056 & 0.077 \\
\hline & 243 & 0.042 & 0.038 & & 230 & 0.056 & 0.026 \\
\hline & 247 & 0.486 & 0.372 & & 232 & 0.000 & 0.013 \\
\hline & 251 & 0.361 & 0.474 & & 234 & 0.000 & 0.013 \\
\hline & 255 & 0.042 & 0.038 & & & & \\
\hline & 259 & 0.042 & 0.000 & B121-52 & 339 & 0.014 & 0.000 \\
\hline & 263 & 0.014 & 0.077 & & 343 & 0.069 & 0.103 \\
\hline & & & & & 345 & 0.222 & 0.000 \\
\hline \multirow[t]{12}{*}{ A073-04 } & 350 & 0.069 & 0.000 & & 347 & 0.125 & 0.205 \\
\hline & 358 & 0.014 & 0.115 & & 349 & 0.181 & 0.333 \\
\hline & 360 & 0.194 & 0.013 & & 351 & 0.069 & 0.064 \\
\hline & 362 & 0.111 & 0.090 & & 353 & 0.125 & 0.179 \\
\hline & 364 & 0.431 & 0.218 & & 355 & 0.097 & 0.026 \\
\hline & 366 & 0.042 & 0.115 & & 357 & 0.042 & 0.090 \\
\hline & 368 & 0.042 & 0.269 & & 359 & 0.014 & 0.000 \\
\hline & 370 & 0.056 & 0.115 & & 361 & 0.014 & 0.000 \\
\hline & 372 & 0.028 & 0.013 & & 363 & 0.028 & 0.000 \\
\hline & 374 & 0.000 & 0.038 & & & & \\
\hline & 378 & 0.014 & 0.013 & & & & \\
\hline & & & & B121-58 & 387 & 0.043 & 0.000 \\
\hline \multirow[t]{14}{*}{ A073-29 } & 117 & 0.014 & 0.103 & & 391 & 0.200 & 0.103 \\
\hline & 119 & 0.014 & 0.038 & & 395 & 0.286 & 0.359 \\
\hline & 121 & 0.014 & 0.000 & & 399 & 0.057 & 0.064 \\
\hline & 123 & 0.056 & 0.090 & & 403 & 0.143 & 0.077 \\
\hline & 125 & 0.167 & 0.090 & & 407 & 0.143 & 0.141 \\
\hline & 127 & 0.125 & 0.115 & & 411 & 0.000 & 0.141 \\
\hline & 129 & 0.208 & 0.128 & & 415 & 0.014 & 0.115 \\
\hline & 131 & 0.194 & 0.141 & & 419 & 0.071 & 0.000 \\
\hline & 133 & 0.097 & 0.090 & & 423 & 0.014 & 0.000 \\
\hline & 135 & 0.069 & 0.026 & & 431 & 0.014 & 0.000 \\
\hline & 137 & 0.014 & 0.128 & & 447 & 0.014 & 0.000 \\
\hline & 139 & 0.028 & 0.013 & & & & \\
\hline & 141 & 0.000 & 0.038 & B137-30 & 159 & 0.014 & 0.000 \\
\hline & & & & & 162 & 0.014 & 0.051 \\
\hline
\end{tabular}




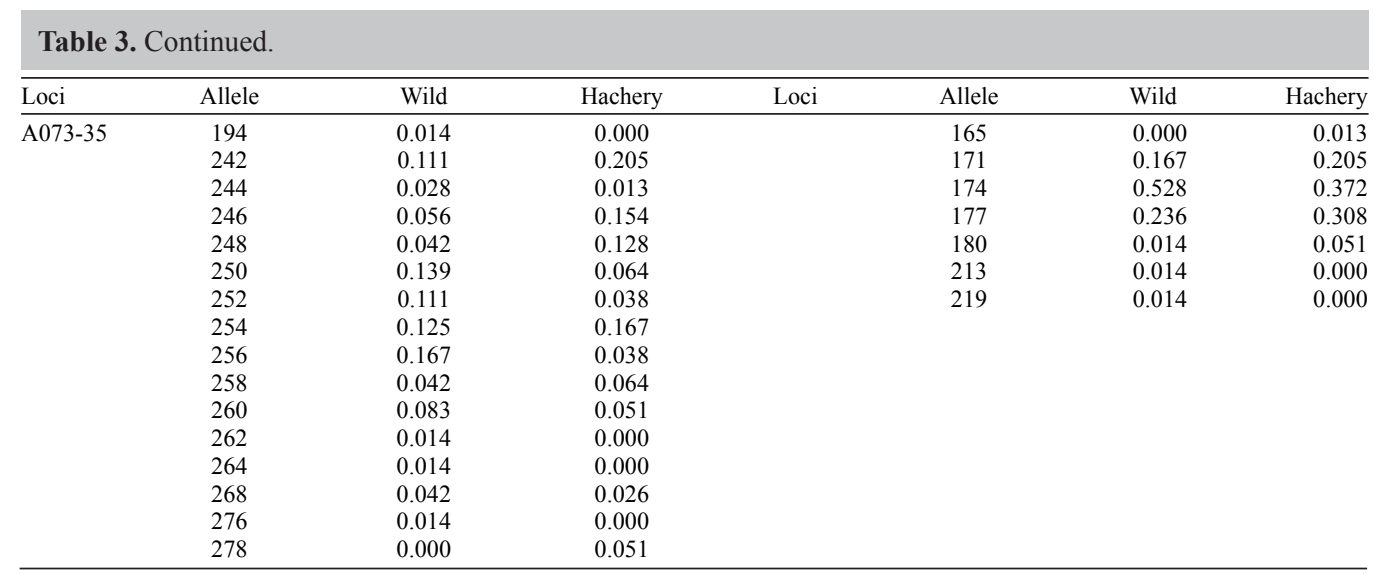
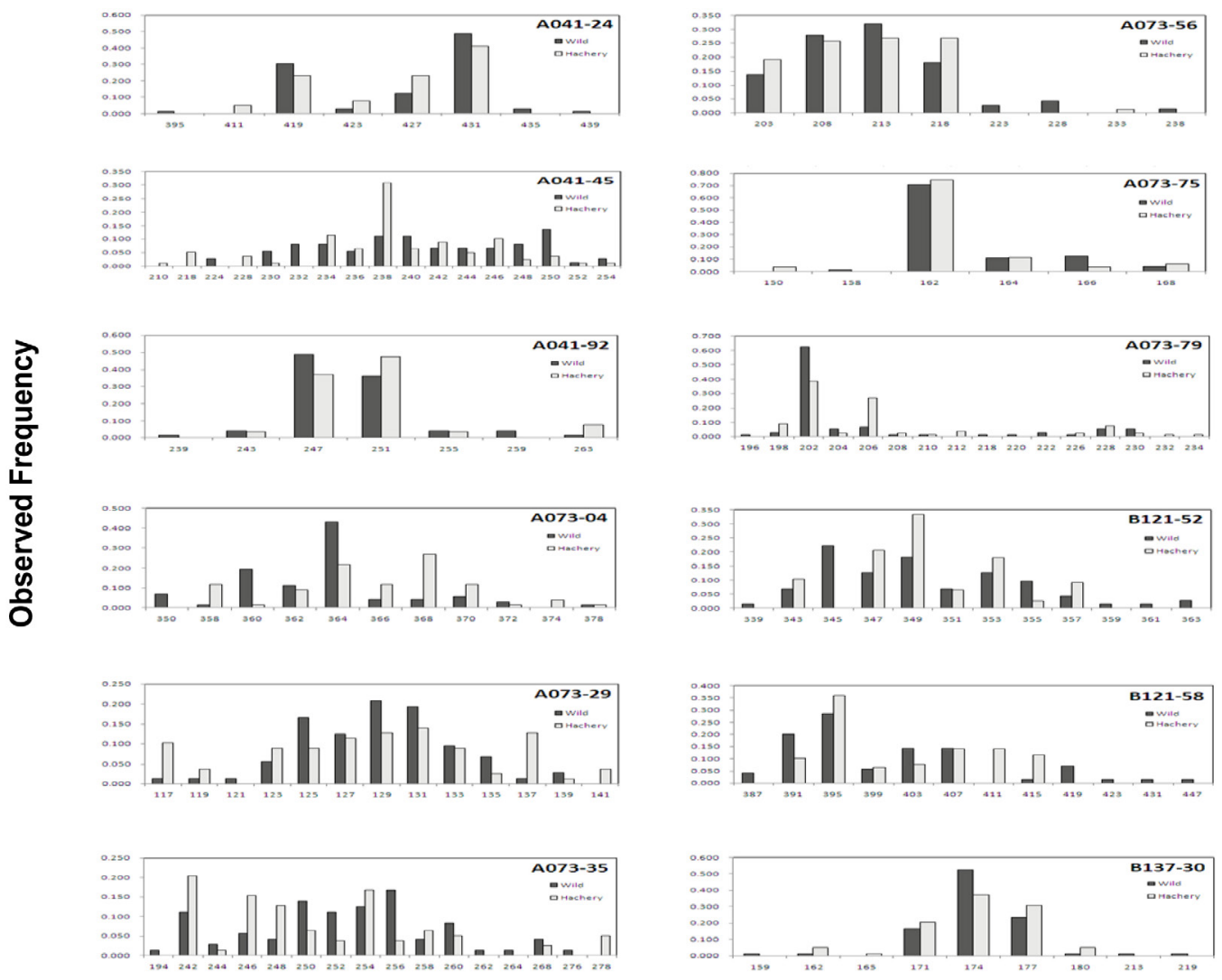

\section{Allele size (bp)}

Figure 1. Allele size frequency distributions of the 12 microsatellite loci in the wild and hatchery-produced populations of Cynoglossus semilaevis used in this study. 
Of the 24 independent loci examined using Hardy-Weinberg analyses, 22 (91.7\%) were generally in accordance with the Hardy-Weinberg proportions. However, 2 cases exhibited significant deviations from the HWE after an adjustment of the P values across the 12 loci using the sequential Bonferroni method for multiple observations (Rice, 1989). Two deviations from equilibrium were observed at 2 loci; B121-58 for the wild sample and A073-04 for the hatchery-produced sample (Table 2). These departures resulted from a deficit in heterozygosity, and no excess heterozygosity was detected in either population at any of the loci tested.

\section{Genetic relationships between populations}

Genetic differentiation between the wild and transplanted hatchery-produced populations of $C$. semilaevis was estimated using $F_{\mathrm{ST}}$ and $R_{\mathrm{ST}}$. The global multilocus $F_{\mathrm{ST}}$, including all loci, was estimated to be $0.025(\mathrm{P}<0.01)$ and the $R_{\mathrm{ST}}$ value was $0.014(\mathrm{P}<0.01)$, indicating genetic differentiation between the 2 populations. The AMOVA of all 12 microsatellites revealed similar results to the FSTAT analysis regarding variation within individuals (95.78\%; $\mathrm{P}=0.056)$, among individuals within populations $(1.74 \% ; \mathrm{P}=0.194)$, and among populations $(2.48 \% ; \mathrm{P}=0.000)$. The AMOVA revealed significant genetic differentiation between the 2 sample sets, although the low genetic variation was explained by the "among populations" hierarchical level $(2.48 \%)$. Thus, the low differentiation between the wild and hatchery-produced populations is supported by AMOVA (Table 4).

Genetic differentiation between the 2 populations was also observed following pairwise comparisons of allelic and genotypic frequencies. The comparisons revealed that, of the 24 pairs of locus-population cases, 16 cases were significantly different for both the allelic and genotypic frequencies following sequential Bonferroni corrections. The significant changes were observed at 8 loci (A041-24, A041-45, A073-04, A073-29, A073-35, A073-79, B12152 , and B121-58) of the 12 loci screened in allelic and genotypic frequencies between the 2 populations.

\begin{tabular}{|c|c|c|c|c|}
\hline Source of variation & Sum of squares & Variance components & Percentage variation (\%) & $P$ value \\
\hline Among populations & 13.237 & 0.115 & 2.48 & 0.000 \\
\hline Among individuals with population & 336.390 & 0.081 & 1.74 & 0.194 \\
\hline Within individuals & 333.500 & 4.447 & 95.78 & 0.056 \\
\hline Total & 683.127 & 4.643 & & \\
\hline
\end{tabular}

\section{DISCUSSION}

The use of multiplex PCR assays to screen microsatellite variations is a robust, economically efficient, and rapid approach to obtaining population genetic data. Despite its costeffectiveness, multiplexing is rarely used, apparently because of a general apprehension that this process increases the complexity of microsatellite genotyping (Neff et al., 2000). With the current protocol, it is possible to optimally analyze 12 microsatellite markers at minimum cost, which is important for the development of an international database on microsatellite variation in tongue sole. Despite the time required for their development, multiplex microsatellite assays should prove valuable when large numbers of fish must be screened. Here, a powerful and 
cost-efficient tool to acquire genetic data for tongue sole is provided using 12 microsatellite loci distributed in 3 PCRs, which may useful for genetic characterization studies.

In this study, genetic variation within the wild population of C. semilaevis (mean $N_{\mathrm{A}}=$ 10.08 , mean $H_{\mathrm{E}}=0.72$ ) was lower compared to the reported variation (mean $N_{\mathrm{A}}=19.96 \pm 6.6$, mean $H_{\mathrm{E}}=0.77 \pm 0.19$ averaged from 12 species) for other marine fish species (DeWoody and Avise, 2000). Similar genetic variability has been reported for this species (Sha et al., 2011), as well as other marine species, including Korean black rockfish (Sebastes inermis) and Korean starry flounder (Platichthys stellatus). This observation indicates that demersal fish are less diverse compared to other migratory fishes (An et al., 2011a, b; Sha et al., 2011).

When the level of diversity in the hatchery-produced population transplanted from China was compared with that of the wild population, there were no significant differences in the average number of alleles per locus or average $H_{\mathrm{E}}$. However, on average, a $17.3 \%$ reduction of alleles per locus and a $41.3 \%$ reduction of unique alleles per locus were observed in the hatchery-produced population, with a slightly lower level of heterozygosity. This reduction in genetic variability in the hatchery-produced population is consistent with previous reports (e.g., Hutchings and Fraser, 2008) that, in hatchery strains, the probability of the loss of rare alleles is high (Allendorf, 1986). In fact, the loss of alleles is more important than the change in allele frequencies, because the latter may be changed again by random drift, whereas a lost allele cannot be recovered. Thus, the production of progeny should be based on well-organized broodstock management strategies, in which genetic factors are of vital importance for the production of high-quality seed for marine animals. In general, it is preferable to use fish hatch in hatcheries for artificial reproduction because, in addition to the difficulties of controlling wild-caught fish, whatever trait hatchery-born fish possess that allows them to succeed in the hatchery helped to produce thousands of apparently healthy young offspring. However, this practice may have unintentional negative effects on the genetic variability of the broodstock for the production of high-quality offspring (Allendorf and Ryman, 1987).

Significant deficits relative to HWE were observed in both the wild and hatchery-produced populations. These deficits may reflect several factors, such as the presence of unrecognized null alleles, natural selection acting on genetic markers, mating among relatives, the reduction of heterozygosity in a population caused by a subpopulation structure known as the Wahlund's effect, or a combination of these factors. In the current case, the presence of unrecognized null alleles and natural selection acting on genetic markers are unlikely explanations for the observed heterozygote deficits, because candidates for selection and null alleles, which affect both samples, were excluded before further analysis. In hatchery populations, heterozygote deficiency is commonly caused by a limited number of founders, or founder effects (Lundrigan et al., 2005; Kohlmann et al., 2005). In wild populations, a possible explanation for the heterozygote deficits is some form of assortative mating. Recently, Korean tongue sole populations have declined precipitously as a result of commercial exploitation. This phenomenon would result in a corresponding reduction in effective population size. This low effective population size, in combination with social behavior and heavy fishing activity, might cause some marine species to become exceptionally vulnerable to inbreeding (Hoarau et al., 2005). Hence, the heterozygote deficits observed in this study may have arisen, at least in part, from inbreeding.

The significant differentiation between the 2 populations, in particular, the number of private alleles, is probably related to a number of factors, such as habitat fragmentation, reduction in the effective number of contributing parents, and the effects of artificial selection on hatchery 
progeny. Hence, genetic drift has probably played an important role in the loss of genetic diversity, and in the differentiation between wild and hatchery-produced populations. Because this study was limited by the number of populations screened, the genetic diversity parameters for each population and the HW disequilibrium at B121-58 in the wild samples might be explained by data from additional sampling, both in terms of sample size and sampling locations. Access to such additional information would allow for a more comprehensive and precise genetic characterization of C. semilaevis. Thus, the present results should be interpreted with caution.

In summary, a method for the molecular screening of tongue soles was developed based on 3 multiplex PCR assays that amplify a total of 12 polymorphic microsatellite loci. Genetic diversity analyses revealed changes in the genetic composition and significant genetic differentiation between wild tongue sole samples from Korea and the hatchery-produced tongue sole population transplanted from China. These results indicate that genetic drift might have negative effects on the reproductive capacity of the stock, because genetic factors are important in the production of high quality seed. Therefore, an adequate broodstock strategy might be necessary to guarantee the success of the complete aquaculture of tongue sole in Korea. The information generated by this study may provide a useful genetic basis for future complete culturing plans and for the management of $C$. semilaevis in fisheries.

\section{ACKNOWLEDGMENTS}

Research supported by a grant from the National Fisheries and Development Institute (NFRDI), contribution number \#RP-2013-BT-079. The views expressed herein are those of the authors and do not necessarily reflect the views of NFRDI.

\section{REFERENCES}

Allendorf FW (1986). Genetic drift and the loss of alleles versus heterozygosity. Zoo Biol. 5: 181-190.

Allendorf FW and Ryman N (1987). Genetic Management of Hatchery Stocks. (Ryman N and Utter F, eds.) Population Genetics and Fishery Management, Washington Sea Grant, University of Washington Press, Seattle, 141-159.

Amos W, Wilmer JW, Fullard K, Burg TM, et al. (2001). The influence of parental relatedness on reproductive success. Proc. R. Soc. London B 268: 2021-2027.

An HS, Byun SG, Kim YC, Lee JW, et al. (2011a). Wild and hatchery populations of Korean starry flounder (Platichthys stellatus) compared using microsatellite DNA markers. Int. J. Mol. Sci. 12: 9189-9202.

An HS, Kim EM, Lee JH, Noh JK, et al. (2011b). Population genetic structure of wild and hatchery black rockfish Sebastes inermis in Korea, assessed using cross-species microsatellite markers. Genet. Mol. Res. 10: 2492-2504.

An HS, Lee JW and Dong CM (2012a). Population genetic structure of Korean pen shell (Atrina pectinata) in Korea inferred from microsatellite marker analysis. Genes Genomics 34: 681-688.

An HS, Lee JW and Hong SW (2012b). Application of novel polymorphic microsatellite loci identified in the Korean Pacific abalone (Haliotis diversicolor supertexta (Haliotidae)) in the genetic characterization of wild and released populations. Int. J. Mol. Sci. 13: 10750-10764.

Blanco Gonzalez E, Aritaki M and Taniguchi N (2012). Microsatellite multiplex panels for population genetic analysis of Red Sea bream Pagrus major. Fish. Sci. 78: 603-611.

Caballero S, Cardenosa D, Soler G and Hyde J (2012). Application of multiplex PCR approaches for shark molecular identification: feasibility and applications for fisheries management and conservation in the Eastern Tropical Pacific. Mol. Ecol. Resour. 12: 233-237.

Chen SL, Tian YS, Yang JF, Shao CW, et al. (2009). Artificial gynogenesis and sex determination in half-smooth tongue sole (Cynoglossus semilaevis). Mar. Biotechnol. 11: 243-251.

Deng SP, Chen SL, Xu JY and Liu BW (2009). Molecular cloning, characterization and expression analysis of gonadal P450 aromatase in the half-smooth tongue-sole, Cynoglossus semilaevis. Aquaculture 287: 211-218.

DeWoody JA and Avise JC (2000). Microsatellite variation in marine, freshwater and anadromous fishes compared with 
other animals. J. Fish Biol. 56: 461-473.

Excoffier L, Smouse PE and Quattro JM (1992). Analysis of molecular variance inferred from metric distances among DNA haplotypes: Application to human mitochondrial DNA restriction data. Genetics 131: 479-491.

Excoffier L, Laval G and Schneider S (2007). Arlequin (version 3.0): an integrated software package for population genetics data analysis. Evol. Bioinform. Online 1: 47-50.

Frankham R, Ballou J and Briscoe D (2002). Introduction to Conservation Genetics. Cambridge University Press, Cambridge.

Goudet J, Raymond M, De Meeus T and Rousset F (1996). Testing differentiation in diploid populations. Genetics 144: 1933-1940.

Han HS, Nam BH, Kang JH, Kim YK, et al. (2012). Genetic variation in wild and cultured populations of the sea squirt Halocynthia roretzi inferred from microsatellite DNA analysis. Fish. Aquat. Sci. 15: 151-155.

Hoarau G, Boon E, Jongma DN, Ferber S, et al. (2005). Low effective population size and evidence for inbreeding in an overexploited flatfish, plaice (Pleuronectes platessa L.). Proc. Biol. Sci. 272: 497-503.

Hong SE, Kim JK, Yu JN, Kim KY, et al. (2012). Genetic variation in the Asian shore crab Hemigrapsus sanguineus in Korean coastal waters as inferred from mitochondrial DNA sequences. Fish. Aquat. Sci. 15: 49-56.

Hutchings JA and Fraser DJ (2008). The nature of fisheries- and farming-induced evolution. Mol. Ecol. 17: 294-313.

Kalinowski ST, Taper ML and Marshall TC (2007). Revising how the computer program CERVUS accommodates genotyping error increases success in paternity assignment. Mol. Ecol. 16: 1099-1106.

Kohlmann K, Kersten P and Flajshans M (2005). Microsatellite-based genetic variability and differentiation of domesticated, wild and feral common carp (Cyprinus carpio L.) populations. Aquaculture 247: 253-266.

Lee HJ and Hur SB (2012). Comparison between phylogenetic relationships based on 18S rDNA sequences and growth by salinity of Chlorella-like species (Chlorophyta). Fish. Aquat. Sci. 15: 125-135.

Lundrigan TA, Reist JD and Ferguson MM (2005). Microsatellite genetic variation within and among arctic charr (Salvelinus alpinus) from aquaculture and natural populations in North America. Aquaculture 244: 63-75.

Miao GD, Liu HW, Ma HY, Chen SL, et al. (2011). Isolation and characterization of 54 polymorphic microsatellite loci for half-smooth tongue sole, Cynoglossus semilaevis. J. World Aquac. Soc. 42: 462-467.

Neff BD, Fu P and Gross MR (2000). Microsatellite multiplexing in fish. Trans. Am. Fish. Soc. 129: 584-593.

NFRDI, National Fisheries Research and Development Institute (2010). The R \& D Report of NFRDI. National Fisheries Research and Development Institute, Busan.

Olafsson K, Hjorleifsdottir S, Pampoulie C, Hreggvidsson GO, et al. (2010). Novel set of multiplex assays (SalPrint15) for efficient analysis of 15 microsatellite loci of contemporary samples of the Atlantic salmon (Salmo salar). Mol. Ecol. Resour. 10: 533-537.

Pan G and Yang J (2010). Analysis of microsatellite DNA markers reveals no genetic differentiation between wild and hatchery populations of Pacific threadfin in Hawaii. Int. J. Biol. Sci. 6: 827-833.

Rice WR (1989). Analyzing tables of statistical tests. Evolution 43: 223-225.

Rousset F (1996). Equilibrium values of measures of population subdivision for stepwise mutation processes. Genetics 142: $1357-1362$.

Rousset F (2008). Genepop'007: a complete re-implementation of the genepop software for Windows and Linux. Mol. Ecol. Resour. 8: 103-106.

Sha ZX, Luo XH, Liao XL, Wang SL, et al. (2011). Development and characterization of 60 novel EST-SSR markers in half-smooth tongue sole Cynoglossus semilaevis. J. Fish Biol. 78: 322-331.

Slatkin M and Excoffier L (1996). Testing for linkage disequilibrium in genotypic data using the Expectation-Maximization algorithm. Heredity 76 (Pt 4): 377-383.

Van Oosterhout C, Hutchinson WF, Wills DPM and Shipley P (2004). MICRO-CHECKER: software for identifying and correcting genotyping errors in microsatellite data. Mol. Ecol. Notes 4: 535-538.

Wang L, Meng Z, Liu X, Zhang Y, et al. (2011). Genetic diversity and differentiation of the orange-spotted grouper (Epinephelus coioides) between and within cultured stocks and wild populations inferred from microsatellite DNA analysis. Int. J. Mol. Sci. 12: 4378-4394.

Wang X, Zhang Q, Sun X, Yin G, et al. (2008). Isolation and characterization of 64 novel microsatellite markers from a fosmid library of female half-smooth tongue sole (Cynoglossus semilaevis). Mol. Ecol. Resour. 8: 1303-1306.

Weir BS and Cockerham CC (1984). Estimating F-statistics for the analysis of population structure. Evolution 38: 13581370.

Wilcoxon F (1945). Individual comparisons by ranking methods. Biometrics Bull. 1: 80-83.

Yoon MG, Jung JY, Nam YK and Kim DS (2011). Genetic diversity of thread-sail filefish Stephanolepis cirrhifer populations in Korean coastal waters inferred from mitochondrial DNA sequence analysis. Fish. Aquat. Sci. 14: 16-21. 